\title{
INFRAPUBIC VERSUS SUBCORONAL SEMI-RIGID PENILE PROSTHESIS IMPLANTATION: A PROSPECTIVE STUDY
}

\author{
By \\ Abd El-Rahman Awadeen ${ }^{1 *}$ and Saadeddin Ali $^{2}$ \\ Departments of Plastic \& Reconstructive Surgery ${ }^{1}$, and Andrology \& Dermatology ${ }^{2}$, \\ Faculty of Medicine, Al-Azhar University, Cairo, Egypt \\ *Corresponding author: Abd El-Rahman Awadeen, \\ Mobile: 01001110592, E-mail: abdelrahmanawadeen.206@ azhar.edu.eg
}

\begin{abstract}
Background: Medical treatment accomplished good results in the treatment of erectile dysfunction (ED). However, these results were temporary, whereby approximately $80 \%$ of the patients experienced drop out. Penile prosthesis insertion is an outstanding treatment for patients with ED who are refectory to medical treatment or those who desired to leave off pharmacotherapy to gain lasting treatment.
\end{abstract}

Objectives: To assess the safety, efficacy, and sexual and psychological satisfaction among patients with ED who were subjected to subcoronal or infrapubic penile prosthesis implantation.

Patients and Methods: The present study was a prospective case-control study that was carried out at AlAzhar University Hospitals through the entire period of 2016 to 2020. Men with ED that did not respond to medical treatment and had vasculogenic impotence based on penile duplex were included in the study. All patients were submitted to clinical evaluation comprised of detailed sexual and urological history, and physical evaluation. All patients were subjected to frequent follow-up assessment visits for six months after the surgery.

Results: This study included a total of 18 patients with ED. Out of them, $9(50 \%)$ patients were subjected to the infrapubic approach, while $9(50 \%)$ patients were treated with the subcoronal approach. Three months postoperatively, all men revealed an average penile length at maximum inflation of $13.4 \mathrm{~cm}(9.3-17.5 \mathrm{~cm})$. This status was continued for six months in which no patient lost his penile length. Among patients treated with the subcoronal approach, one patient developed penile extrusion one and half months post-operatively due to wound dehiscence secondary to uncontrolled DM. As for the infrapubic group, a patient developed superficial infection and wound dehiscence and responded to antibiotic use and secondary suturing. Another case developed a hypertrophic scar.

Conclusion: Erectile dysfunction can be safely and effectively treated by implantation of the penile prosthesis by the subcoronal approach. This approach achieved high satisfactory functional, aesthetic, and psychological outcomes relative to the infrapubic approach.

Keywords: Erectile Dysfunction. Subcoronal, Infrapubic, Penile Prosthesis.

\section{INTRODUCTION}

Penile prosthesis accomplished superior sexual satisfaction for both patient and partner when compared with other therapeutic methods of ED
(Bettocchi et al., 2010). Based on these benefits, the American Urological Association proposed that all erectile dysfunction patients should be aware of the potential advantages of penile 
prothesis as a therapeutic approach (Burnett et al., 2018).

Abundant variations of the inflatable prosthesis procedures have been evolved comprehending penoscrotal, suprapubic, perineal, infrapubic and subcoronal approaches (Trost et al., 2015). The subcoronal approach has the benefits of low risk of crossover during corporal dilatation along with preferable cosmetic results and low risk of infection (Weinberg et al., 2016). The infrapubic approach has two main advantages apart from the capability to implant the reservoir more quickly under immediate vision via the same incision, as well as avoidance of additional incisions to the scrotum (Karpman, 2012 and Vollstedt et al., 2017). Conversely, numerous disadvantages had been reported such as restricted distal corporal exposure, damage to the dorsal nerve of the penis, and difficulties to access to the most dependent portion of the scrotum to fix the pump (Kramer \& Chason, 2010 and Antonini et al., 2016). Throughout the literature search, no study has been implemented to compare the outcomes of the subcoronal and the infrapubic approaches for the treatment of ED.

The current investigation was conducted to reveal the safety, efficacy, and sexual and psychological satisfaction among patients with ED who were subjected to the subcoronal or the infrapubic penile prosthesis implantation.

\section{PATIENTS AND METHODS}

The present study was a prospective case-control study that was carried out at Al-Azhar University Hospitals through the entire period of 2016 to 2020. All clinical and surgical procedures were conducted along with the recommendations of the ethical research board committee of the Faculty of Medicine, Al-Azhar University, Cairo, Egypt, after an obvious explanation of the probable consequences and adverse events of the surgical procedures. All patients were aware of the potential adverse events apart from the loss of penile length, mechanical reliability, infection rates, and the risk of injury to adjacent structures such as the urethra, bladder, bowel, and vessels.

Prior to study implementation, all patients assigned informed consents to elucidate their agreement to participate in the current investigation and their prior knowledge of the possible sequels. Men with ED who did not respond to medical treatment for at least six months and had vasculogenic impotence based on penile duplex were included in the study. Penile duplex was performed by the andrologist who interpret the results of it. On the other hand, patients with urinary incontinence, penile deformities, patients subjected to previous penile or urethral surgery, patients subordinated to simultaneous surgeries for congenital or acquired recurvatum, marked obese candidates, patients with neurogenic impotence, and patients with massive obstructive urinary tract symptoms were omitted. Prior to the surgical intervention, patients with intense infection, principally urinary tract infection or genital skin infection or those who unfit for surgery, were excluded.

Preoperative detailed counseling with patients about their medical condition and details of surgical intervention was implemented. They received postoperative instructions discussing the 
benefits of the procedure to realize the satisfaction of the patient and outcomes which normalize the sexual cycle. In some cases, we required counseling in the presence of his wife after his permission. The counseling was done in three sessions from the first meeting, the second session after obtaining the results of the investigations, and the last preoperative to roll out any criteria of psychological illness. All clinical complaints from the wife about vaginal looseness or widening, especially in repeated pregnancy cases, were put into consideration to achieve the normal sexual cycle to correct the problem from a comprehensive overview of both partners.

All patients were submitted to clinical evaluation comprised of detailed sexual and urological history and physical evaluation. The laboratory assessment was executed, including urine analysis, serum testosterone, prolactin, prostate-specific antigen levels, blood profile, liver functions, renal functions, fasting blood sugar, and glycosylated hemoglobin.

Preoperatively, a doppler ultrasound assessment was done for all patients to appreciate the penile hemodynamics before and after intracavernous injection of prostaglandin E1. Additionally, erectile length was assessed via a flexible tape that extended from the penis up to the coronal sulcus.

\section{Surgical procedure:}

Infrapubic approach: Closure to the penile root, a transverse skin incision of $2.5-4 \mathrm{~cm}$ was performed at the level of the lower border of the symphysis pubis. The corpora were exposed using two retractors, emphasizing avoiding the injury of the neurovascular bundle and suspensory ligaments. Two lateral stay silk sutures were applied in the starting corpora then corporotomy vertical incision $(2 \mathrm{~cm})$ was performed. Furthermore, subtunical dilation of the corpora with penile stretching using heggar dilators in an upward and lateral direction to avoid urethral injury. The measurements were taken while the penis was maximally lengthened. Continuous irrigation with gentamycin and saline proximally and distally was implemented. After adequate measurements, the cylinder was positioned. Corpora were closed in a continuous pattern followed by the closure of the remaining layers separately (Figure 1). 


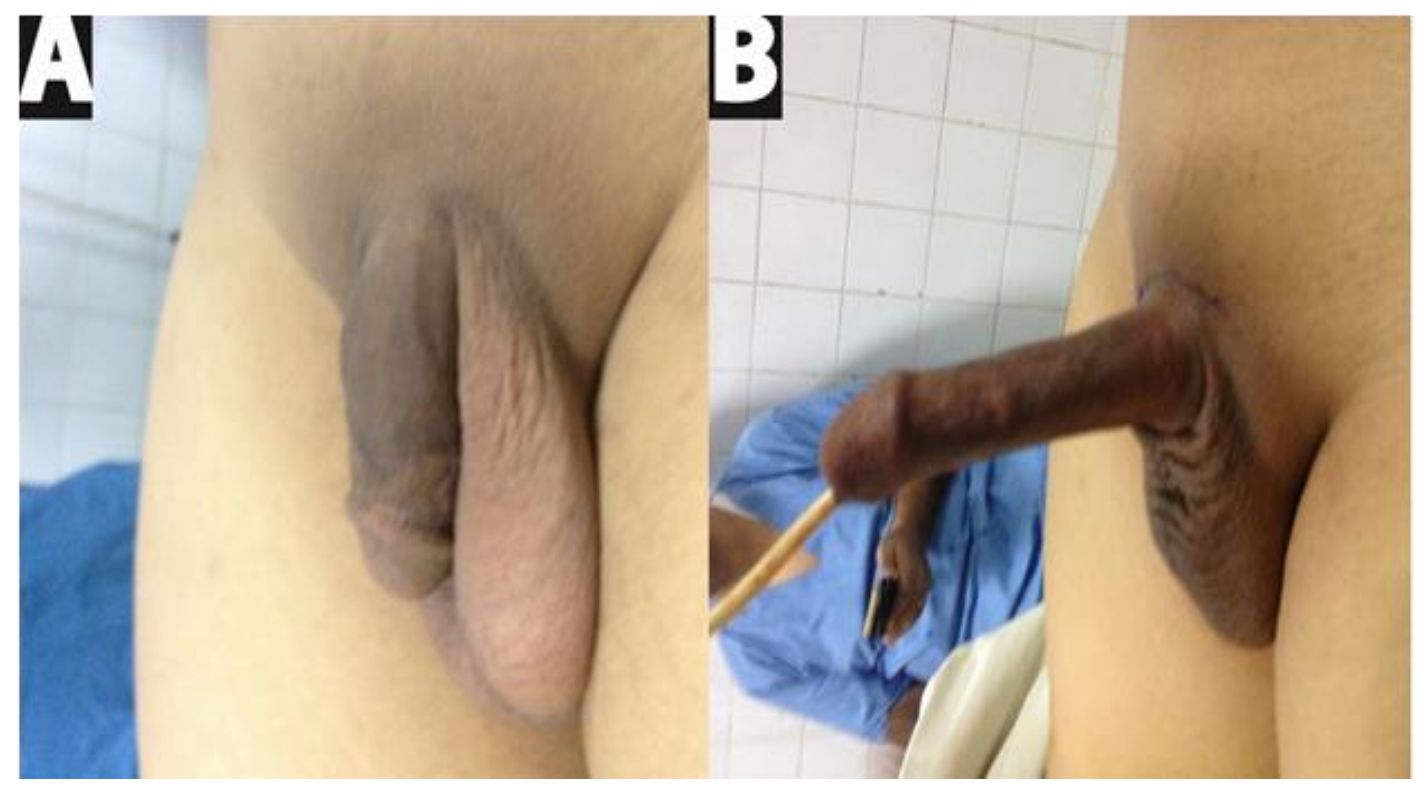

Figure (1): Patient with ED who subjected to infrapubic approach. A. During preoperative evaluation, B. Immediate post-operative results with transverse skin incision after implant positioning.

Subcoronal approach: A distal dorsal semi circumcisional " subcoronal" skin incision was performed $2 \mathrm{~cm}$ proximal to the coronal sulcus of glans penis. The glans penis was, subsequently, grasped in the surgeon's non-dominant hand, and a special gauze was used to dissect in the subdartos plan towards the penis base. Stay sutures of braided polyglactin (Vicryll 00) were positioned to retract the dissected flap followed by corpotomy. Furthermore, Metzenbaum scissors were passed away in a posterior direction to the mid glans. The furlow instrument was passed proximally and distally into the channel opened by the scissors to assess the distal and proximal measurements. After adequate measurements, the proximal end of the prosthesis was embedded into the corpora close to the penoscrotal junction. The distal end of the prosthesis was pulled through the remaining corpora towards the mid glans (Figure 2). 


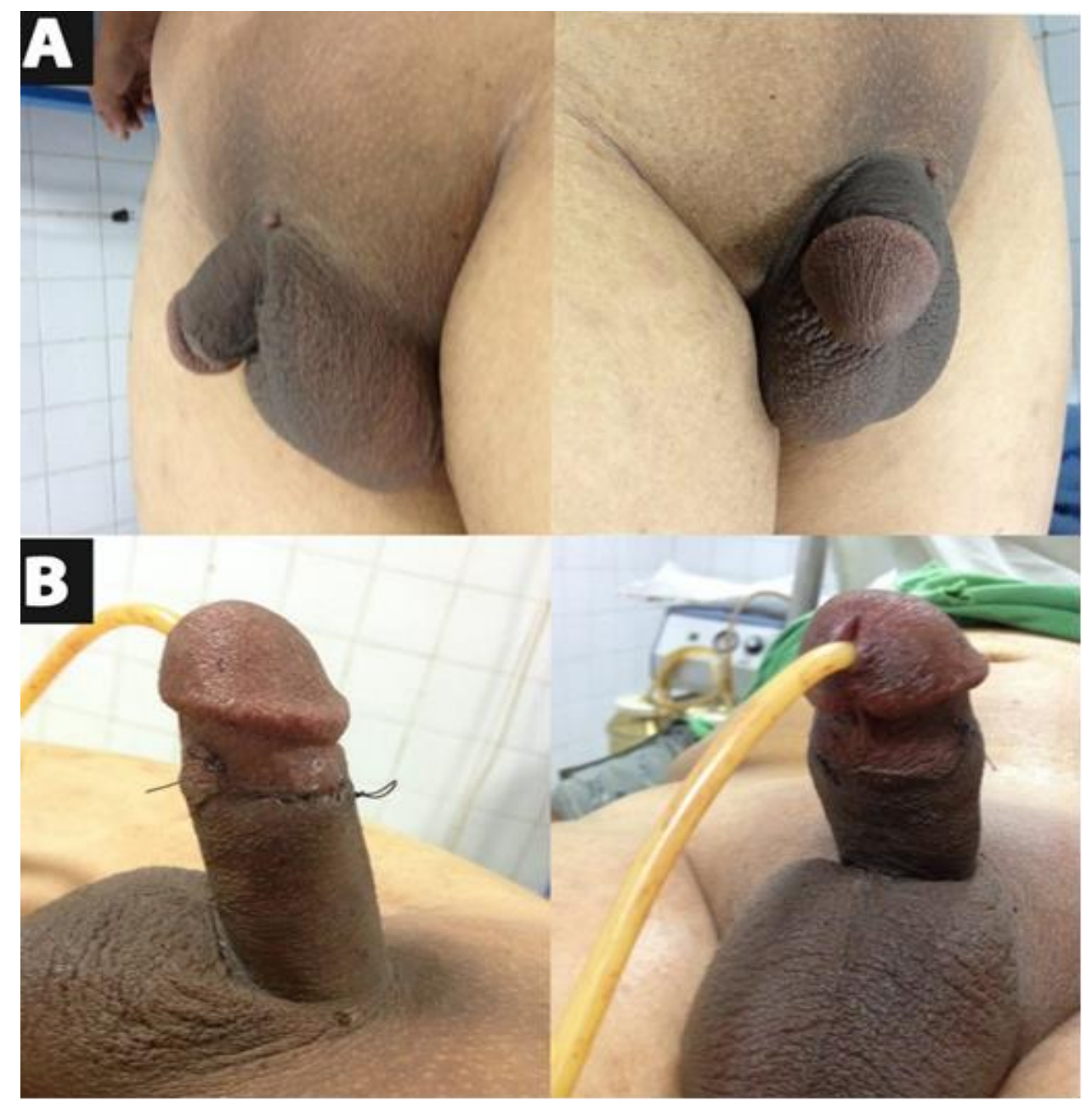

Figure (2): Patient with ED who was subjected to subcoronal approach. A. During Preoperative evaluation, B. Immediate results after closing of the subcoronal incision at the end of surgery.

All patients received broad-spectrum antibiotics and alpha-blockers to decrease post-intervention urinary manifestations. All patients were subjected to frequent follow-up assessment visits for six months after the surgery.

\section{Statistical analysis:}

Continuous normally distributed data were reported in the form of mean, and standard deviation (SD), and its related groups were compared using independent sample t-test. Categorical variables were expressed using number and percentage and its particular groups were compared using Fisher's exact test. The overall statistically significant difference was established at $\mathrm{p}<0.05$. Statistical analysis was performed using SPSS software version 25 for Windows (SPSS Inc., Chicago, IL, USA). 


\section{RESULTS}

Patients' demographic characteristics: This study included a total of 18 patients with ED. Out of them, 9 (50\%) patients were subjected to the infrapubic approach, while $9(50 \%)$ patients were treated with the subcoronal approach. The mean age of the included patients was $53.5 \pm 9.8$ and
$52.1 \pm 10.6$ years among the infrapubic and the subcoronal groups, respectively. There were $2(22.22 \%)$ diabetic cases within the infraopubic group, in contrast to 3 (33.33\%) patients within the subcoronal group (Table 1).

Table (1): Baseline demographic characteristics of the included patients

\begin{tabular}{|c|c|c|c|}
\hline \multirow{2}{*}{$\begin{array}{ll} & \text { Groups } \\
\text { Variables }\end{array}$} & Infrapubic approach & Subcoronal approach & \multirow{2}{*}{ P-Value } \\
\hline & Mean +SD/Number (\%) & Mean +SD/Number (\%) & \\
\hline Number & 9 & 9 & \\
\hline Age & $53.5 \pm 9.8$ & $52.1 \pm 10.6$ & 0.61 \\
\hline BMI $\left(\mathrm{Kg} / \mathrm{m}^{2}\right)$ & $28.5 \pm 5.4$ & $27.6 \pm 4.8$ & 0.78 \\
\hline \multicolumn{4}{|l|}{ Comorbidities } \\
\hline Diabetes & $2(22.22 \%)$ & $3(33.33 \%)$ & 1 \\
\hline Hypertension & $1(11.11 \%)$ & $2(22.22 \%)$ & 1 \\
\hline
\end{tabular}

\section{Surgical outcomes:}

Three months postoperatively, all men revealed an average penile length at maximum inflation of $13.4 \mathrm{~cm}(9.3-17.5$ $\mathrm{cm})$. This status was continued for six months in which no patient lost his penile length (Figures 3 and 4).

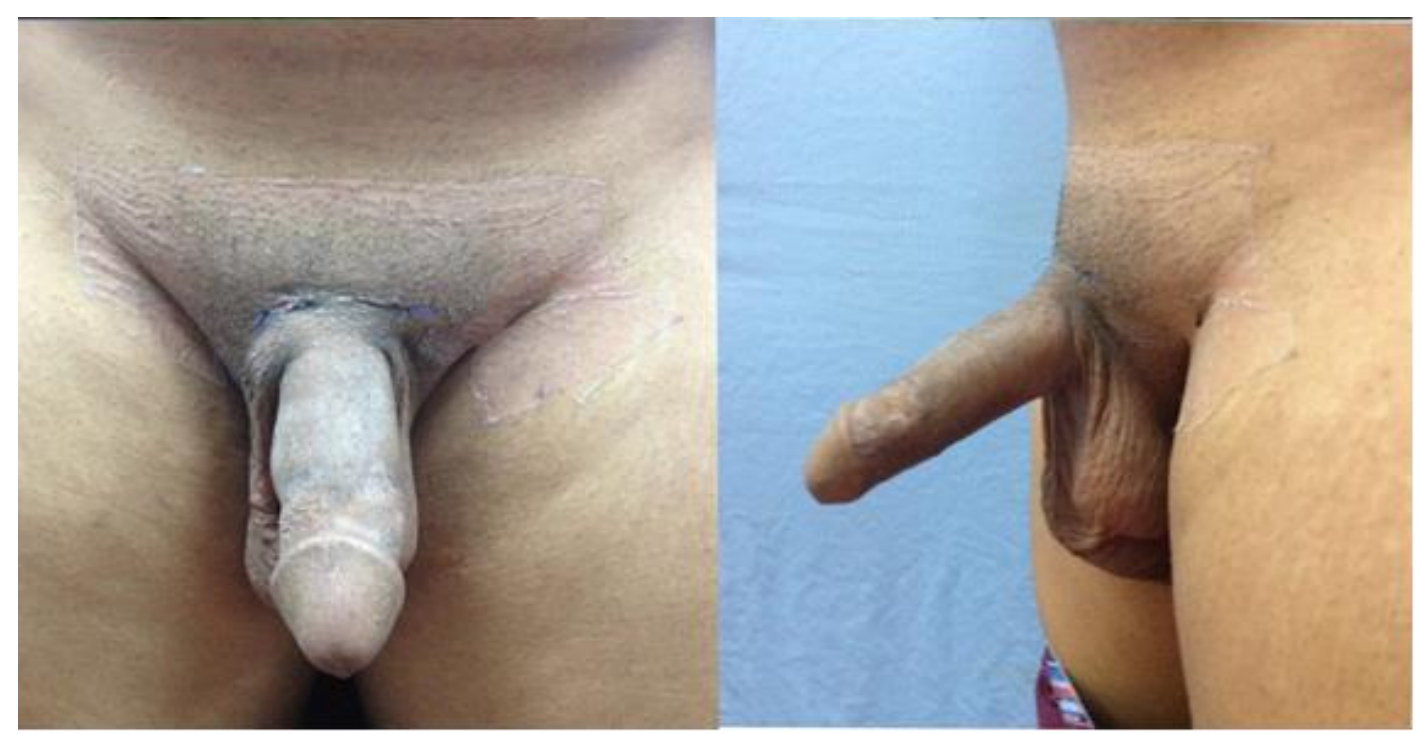

Figure (3): The length of the penis one week after positioning of semi-rigid implant through infrapubic approach 


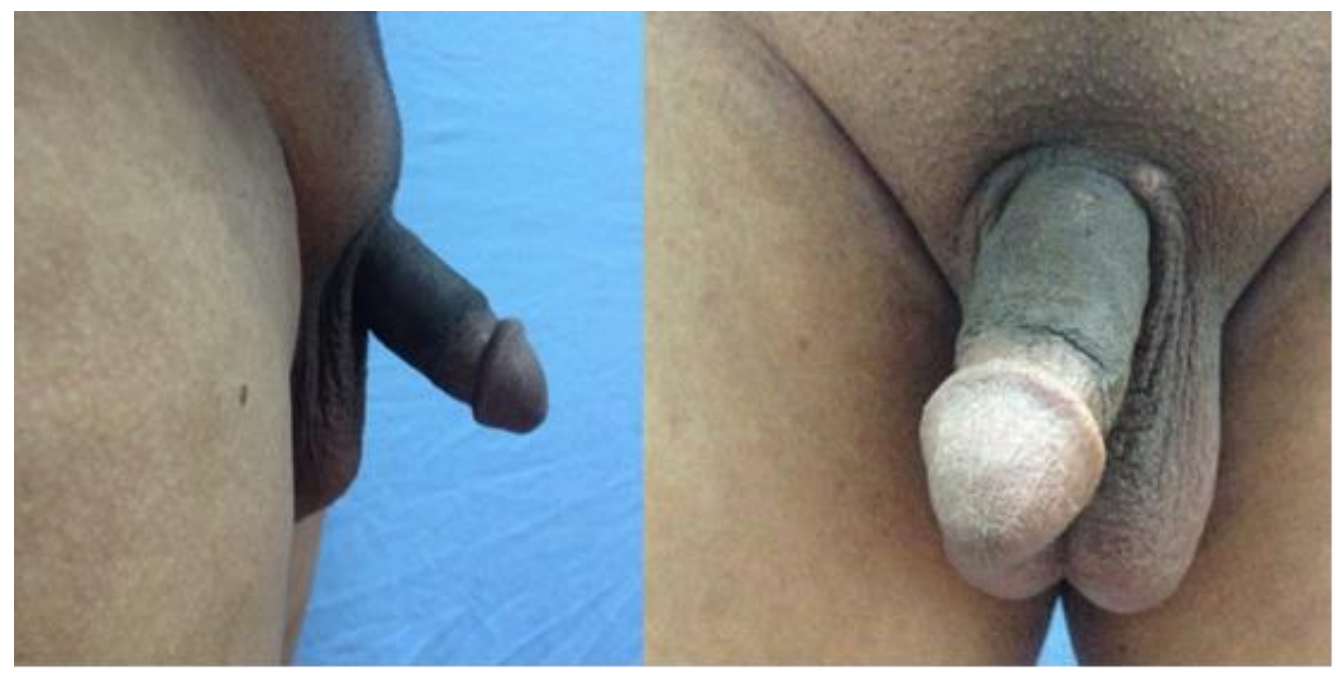

Figure (4): The length of the penis one week after positioning of semi-rigid implant through Subcoronal approach

\begin{abstract}
Among patients treated with the subcoronal approach, one patient developed penile extrusion one and half months postoperatively due to wound dehiscence secondary to uncontrolled DM. Furthermore, three patients were unsatisfied with the penile girth, and after psychiatric consultation, they suggested enhancement penile girth if available to achieve the desired patient's outcome. As the mainline of psychological treatment of these cases, we used autologous fat transfers to augment the girth and giving soft padding around the prosthesis. The fat harvested by Coleman's harvesting cannula from trochanteric area without any use of the tumescent solution and transferred in subcutaneous plan with blunt tip fat injection cannula. The three cases accepted limited fat absorption, which did not exceed $20 \%$ of the injected
\end{abstract}

\section{DISCUSSION}

The inflatable penile prosthesis and implantation techniques witnessed a significant increase with better surgical outcomes and broader acceptance (Bajic et al., 2020). The infrapubic approach is widely used with excellent results; amount with the achievement of patient satisfaction.

As for the infrapubic group, a patient developed a superficial infection and wound dehiscence and responded to antibiotic use and secondary suturing. Another case developed hypertrophic scar and responded to topical intralesional steroid injection one setting followed by three sessions of fractional $\mathrm{Co} 2$ laser for resurfacing. Another patient developed paranesthesia at the incision site. Two cases were unsatisfied by penile girth despite adequate preoperative counseling in the three sessions, but disclosure was mainly due to partner dissatisfaction. There was no need for girth enhancement, but the wife of both patients was complaining of vaginal looseness grade 2, requiring intravaginal fat transfer.

however, the debate existed regarding which approach is the most feasible, safe, and effective. Throughout the era of penile prosthesis, manufactures have continued to improve the outcomes of the penile prosthesis by improving the prosthesis design. Conversely, minimal changes have been proposed for the 
operative techniques to implant the components (Otero et al., 2020 and Saavedra-Belaunde et al., 2020). Therefore, this study was conducted to reveal the outcomes of the subcoronal and the infrapubic approaches for penile prosthesis in patients with ED.

In this study, patients with the subcoronal approach accomplished better functional, cosmetic, and psychological satisfaction relative to those who received the infrapubic approaches. These significant surgical outcomes were also associated with fewer patterns of complications. These findings were concomitant with Weinberg et al., 2016 who reported that modified non-touch subcoronal approach allows easier access to the entire corporal body, allowing the operator to carry out different penile reconstruction surgeries via a single incision (Weinberg et al., 2016). The subcoronal approach is a simple approach with easy accessibility for implant insertion and fitting with a short operative time. The infrapubic procedure is totally away from penile skin, limiting the susceptibility of paresthesia or other wound problem in the penile skin, which hinder the normal sexual act of the patient. It also helps in penile lengthening in cases of the short penis and some cases with excess infrapubic skin, which causes burying of the penile root, and clinical shortening can be excised in a crescentic manner with its doom upward. The excessive skin excision can be advanced in the cephalic direction in a lazy Sshaped scar. In some cases, this approach helps to reduce excess fat in this area, but it requires meticulous dissection. However, the infrapubic approach has golden advantages not solving the ED problem but also helps restore as much as we can the normal anatomy with excellent functional and aesthetic outcomes.

Infection is the most feared complication after penile prosthesis procedures. It is associated with penile shortening, urethral injury, erosions, mechanical failure, and tissue loss. This finding was in parallel with Eid (2011). who found fewer infection patterns associated with the non-touch technique. While the dartos muscle is fully retracted off the corpora during the procedure, many reconstructive surgeries could be performed. These reconstructive procedures previously required further incisions, allowing the surgeon to improve the cosmetic outcomes by performing a single incision. The infrapubic approach is associated with a higher risk of neurovascular bundle injury. To avoid such injury, the infrapubic approach through the dorsal surface of the corpora cavernosa may provide anatomical protection against the injury (Berg, 2011).

The rapidly evolving technology beneath the complexity of penile prosthesis continued to minimize the complications associated with implantation. This makes the prosthesis more effective, reliable, safe, and widely accepted for the treatment of ED with the accomplishment of desired functional outcomes with high satisfaction rates. Despite the evidence obtained in this study, it represents an experience of limited cohort size. Additionally, the short follow-up period limited the capability to assess the long-term outcomes of penile prosthesis with the infrapubic and subcoronal approaches. 
Despite the great satisfaction associated with inflatable devices, certain drawbacks stand barriers against their use. Mechanical deflation, costs, lengthy operative time, more dissection, and experience to avoid nerve injury are all barriers against its employment. With the semi-rigid implants, cost-effectiveness, shorter operative time, and easy applicability are the main advantages.

\section{CONCLUSION}

Erectile dysfunction can be safely and effectively treated by implantation of the penile prosthesis by the subcoronal approach. This approach achieved high satisfactory functional, aesthetic, and psychological outcomes relative to the infrapubic approach. Further studies with randomized controlled design and adequate follow-up periods are required to address the potential limitations of this study.

\section{REFERENCES}

1. Antonini, G., Busetto, G., De Berardinis, E., Giovannone, R., Vicini, P., Del Giudice, F. and Perito, P. (2016): Minimally invasive infrapubic inflatable penile prosthesis implant for erectile dysfunction: evaluation of efficacy, satisfaction profile and complications. International Journal of Impotence Research, 28(1): 4-8.

2. Bajic, P., Mahon, J., Faraday, M., SadeghiNejad, H., Hakim, L., and McVary K. (2020): Etiology of erectile dysfunction and duration of symptoms in patients undergoing penile prosthesis: a systematic review. Sexual Medicine Reviews, 8(2): 333-337.

3. Berg, O. (2011): Infrapubic approach for malleable penile implant. International Brazalian Journal of Urology, 37(1): 94-99.

4. Bettocchi, C., Palumbo, F., Spilotros, M., Lucarelli, G., Palazzo, S., Battaglia, M. and Ditonno, P. (2010): Patient and partner satisfaction after AMS inflatable penile prosthesis implant. The Journal of Sexual Medicine, 7(1pt1): 304-309.

5. Burnett, A. L., Nehra, A., Breau, R. H., Culkin, D. J., Faraday, M. M., Hakim, L. S. and Miner, M. M. (2018): Erectile dysfunction: AUA guideline. The Journal of urology, 200(3): 633-641.

6. Eid, J. (2011): No-touch technique. The Journal of Sexual Medicine, 8(1): 5-8.

7. Karpman, E. (2012): Streamlined approach for infrapubic placement of an inflatable penile prosthesis. Advances in Urology, 9(2): 643-655.

8. Kramer, A. and Chason, J. (2010): Residents at the University of Maryland Medical System provide insight to learning infrapubic approach for IPP surgery: relative benefits but novel challenges exposed in first 15 cases. The journal of sexual Medicine, 7(3): 1298-1305.

9. Otero, J. R., Manfredi, C., and Wilson, S. (2020): The good, the bad, and the ugly about surgical approaches for inflatable penile prosthesis implantation. International Journal of Impotence Research, 3(1): 1-10.

10. Saavedra-Belaunde, J. A., ClavellHernandez, J. and Wang, R. (2020): Epidemiology regarding penile prosthetic surgery. Asian Journal of Andrology, 22(1): 27.

11. Trost, L., Boonjindasup, A., and Hellstrom, W. (2015): Comparison of infrapubic versus transcrotal approaches for inflatable penile prosthesis placement: a multi-institution report. International Journal of Impotence Research, 27(3):86-9.

12. Vollstedt, A., Gross, M. S., Antonini, G. AND Perito, P. E. (2017): The infrapubic surgical approach for inflatable penile prosthesis placement. Translational Andrology and Urology, 6(4): 620-627.

13. Weinberg, A. C., Pagano, M. J., Deibert, C. M, and Valenzuela, R. J. (2016): Subcoronal inflatable penile prosthesis placement with modified no-touch technique: a step-bystep approach with outcomes. The Journal of Sexual Medicine, 13(2): 270-276. 


\section{دراسة مسثقبلية لثقيبيم ثتأيج زراعة اللدعامة القضيبية شبيه الجامدة

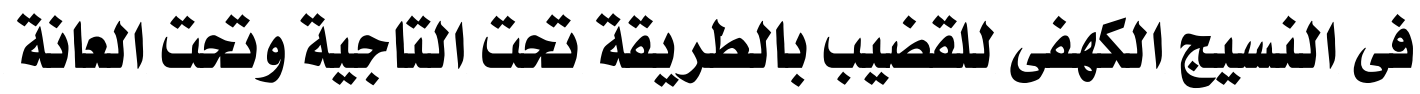 للمرضى اللذيز يعاذوز من ضعف الإثتصاب \\ عبد الرحمن عوضين*، سعد الدين على}

قسمى جراحة التجميل والحروق* و الجلاية والتناسلية، كلية الطب، جامعة الأزهر

E-mail: abdelrahmanawadeen.206@azhar.edu.eg

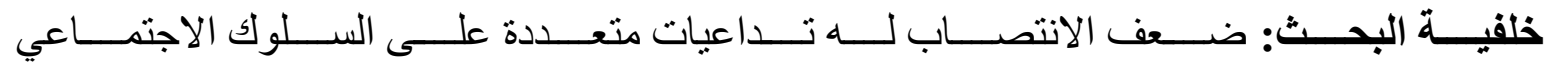

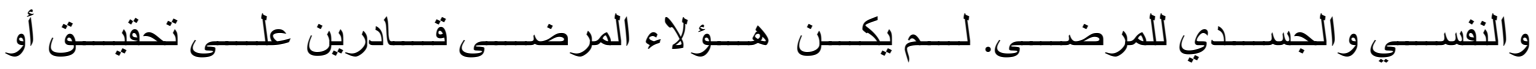

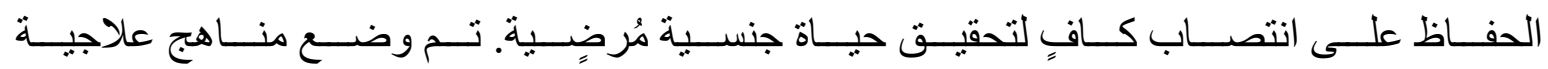

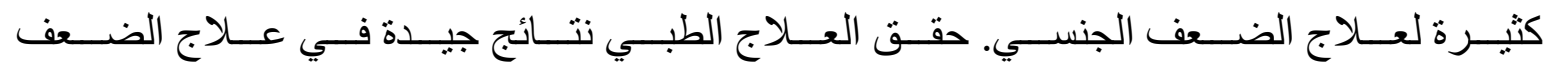

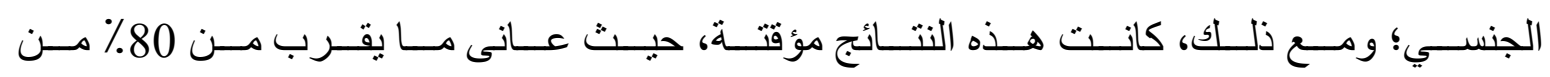

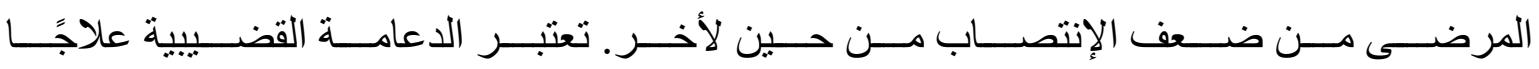

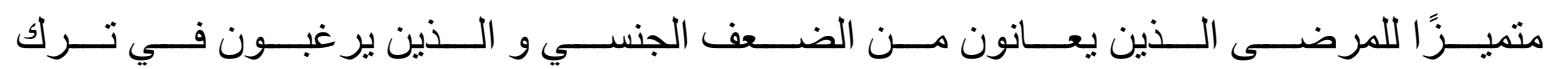
العلاج الدوائي من أجل الحصول على علاج دائم.

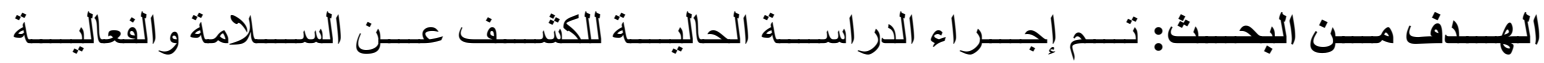

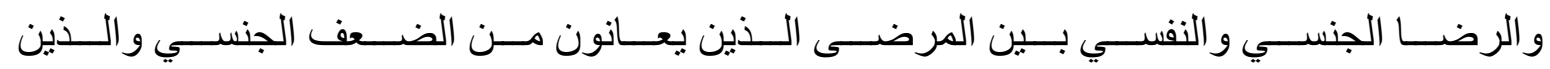

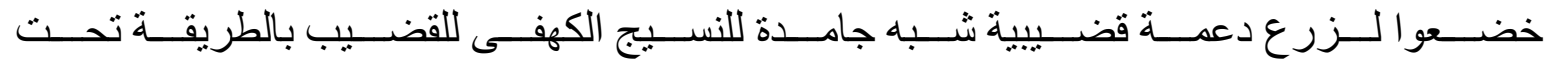
التاجية وبطريقة تحت العانة.

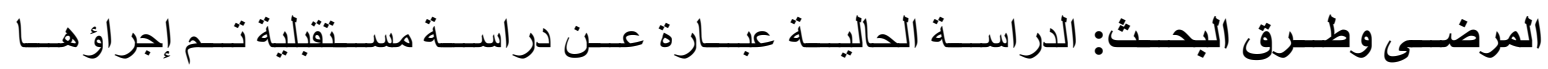

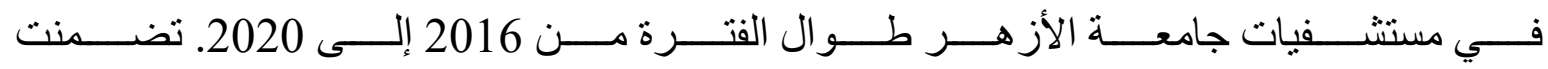

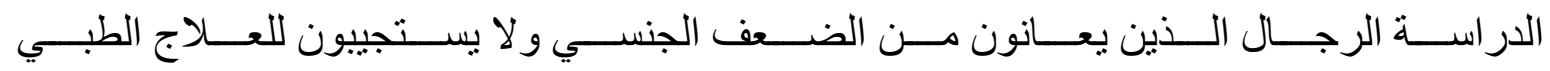

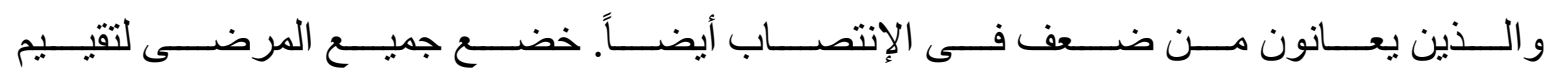

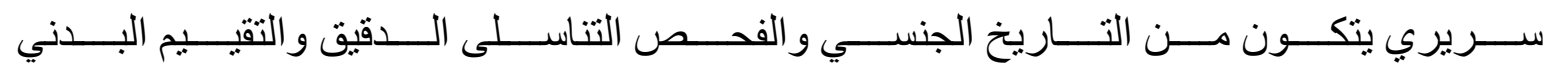
بالإضافة إلى زيار ات منكرة للمتابعة وتقييم لمدة 6 أشهر بعد الجر احة.

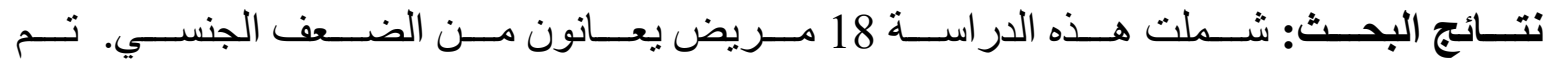

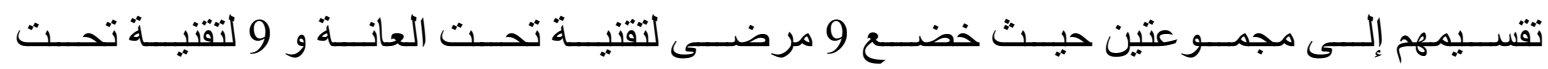




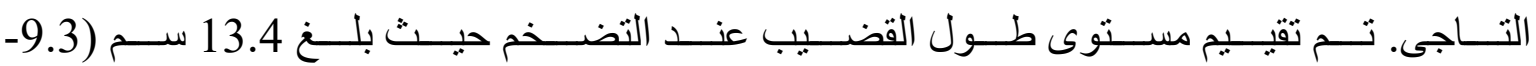

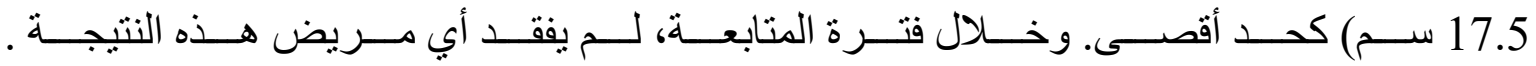

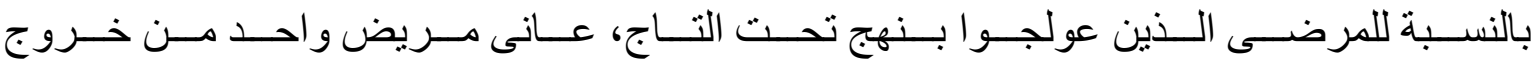

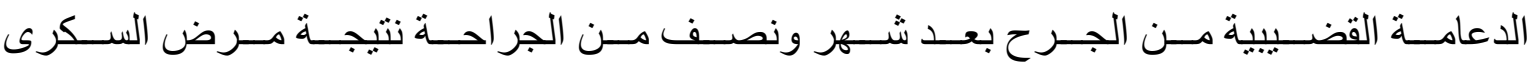

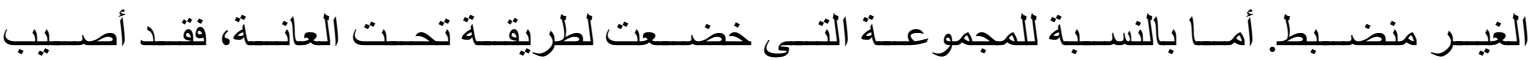

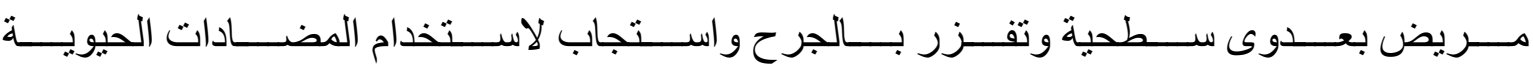
و الخياطة الثانوية بينما عانت حالة أخرى من ظهور ندبة تضخمية.

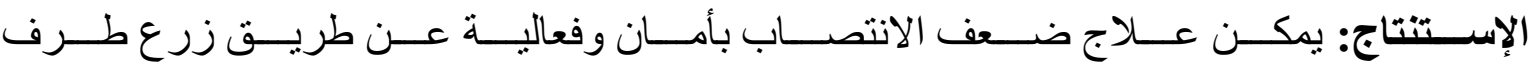

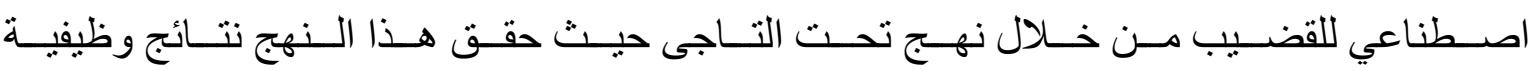
وجمالية ونفسية مرضية عالية، مقارنة بالنهج تحت العانة.

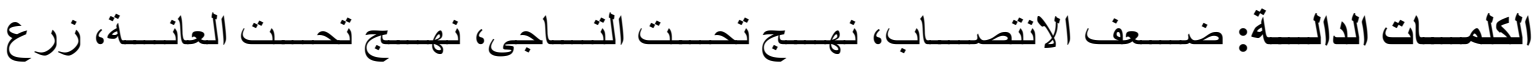
نسيج قضيبى. 